\title{
SERVICE QUALITY, CUSTOMER SATISFACTION, DAN CORPORATE IMAGE TERHADAP CUSTOMER LOYALTY PADA KLINIK KECANTIKAN DI JAKARTA
}

\author{
MEGI TAMIA \\ WIBISONO SOEDIONO \\ Trisakti School of Management, Jl. Kyai Tapa No. 20 Jakarta 11440, Indonesia \\ meggimeggitam@yahoo.co.id, wibisono17@hotmail.com
}

\begin{abstract}
The purpose of this research to aware of the influence of service quality, customer satisfaction, and corporate image, toward customer loyalty on klinik kecantikan erha skin care at Jakarta. This study using regression analysis to analyse data. The research has 100 sample on klinik kecantikan erha skin care. Research used purposive sampling method to determine this study. This study found that service quality, customer satisfaction and corporate image good effect on customer loyalty on klinik kecantikan erha skin care in Jakarta.
\end{abstract}

Keywords: Service quality, customer satisfaction, corporate image, customer loyalty, regression analysis spss

Abstrak: Tujuan penelitian untuk mengetahui adanya pengaruh Service Quality, Customer Satisfaction, dan Corporate Image terhadap Customer Loyalty pada klinik kecantikan Erha skin care di Jakarta. Penelitian ini menggunakan analisis regresi untuk menganalisis data. Sampel penelitian ini sebanyak 100 orang dengan kriteria pernah menggunakan produk/jasa klinik kecantikan Erha skin care. Peneliti menggunakan purposive sampling untuk menentukan sampel penelitan ini. Penelitian ini menemukan bahwa Service Quality, Customer Satisfaction, Corporate Image sangat berpengaruh terhadap Customer Loyalty pada klinik kecantikan Erha skin care di Jakarta

Kata kunci: Service quality, customer satisfaction, corporate image, customer loyalty, regression analysis spss

\section{PENDAHULUAN}

Perawatan kecantikan pada saat ini sudah menjadi kebutuhan bagi setiap orang yang menginginkan kulit yang sehat, khususnya kaum wanita yang menginginkan kecantikan dan kesempurnaan. Gaya hidup kaum wanita pada saat ini menuntut untuk lebih memperhatikan penampilan, untuk itu perawatan kulit sangat penting bagi setiap orang. Terlebih lagi untuk mengatasi berbagai keluhan yang menyebabkan masalah pada kulit yang dapat mengurangi kecantikan, maka itu setiap orang membutuhkan produk dan perawatan yang tepat.
Saat ini banyak sekali produk-produk kecantikan yang beredar dipasaran, seiring dengan itu berbagai perusahaan dibidang kecantikan mulai banyak bermunculan, produk tersebut biasanya berupa obat-obatan yang dikemas dalam berbagai macam bentuk kosmetik untuk digunakan sehari-hari oleh konsumen. Dengan semakin banyaknya perusahaan dibidang kecantikan, mereka seakan-akan berlomba-lomba agar produkproduk kecantikannya dapat diterima oleh pasar dan mempunyai konsumen yang tetap.

Kemajuan pada industri kecantikan di Indonesia saat ini menunjukkan peningkatan. Berdasarkan data Kementerian Perindustrian 
(2016), pertumbuhan pasar industri ini rata-rata mencapai $9,67 \%$ per tahun dalam enam tahun terakhir (2009-2015). Diperkirakan besar pasar (market size) pasar kosmetik sebesar Rp. 46,4 triliun di tahun 2017 ini. Dengan jumlah tersebut, Indonesia merupakan potential market bagi para pengusaha industri kecantikan baik dari luar maupun dalam negeri.

Majalah kartini menjelaskan dalam 10 tahun terakhir industri kecantikan dan perawatan pribadi di Indonesia bertumbuh ratarata $12 \%$ dengan nilai pasar mencapai sebesar 33 triliun Rupiah di tahun 2016. Bahkan di tahun 2020 , industri kecantikan di Indonesia diprediksi akan mengalami pertumbuhan paling besar dibandingkan dengan negara-negara lain di Asia Tenggara. (MajalahKartini.co.id)

Sigma Research Indonesia melakukan penelitian kepada 1200 perempuan Indonesia dengan segmen usia 15-55 tahun. Dari penelitian tersebut terungkap bahwa terdapat beberapa faktor yang menjadi pertimbangan perempuan dalam membeli produk kosmetik. Faktor yang paling besar presentasenya adalah kecocokan formula pada kulit wajah $(79,4 \%)$, kemudian diikuti oleh produk yang tahan lama $(67,4 \%)$, formula ringan $(62,2 \%)$, serta pemilihan warna, halal, harga dengan persentase masing-masing di atas 50\%.

Kecocokan formula pada wajah menjadi pertimbangan utama memilih produk kosmetik oleh wanita di seluruh segmen usia. Sementara produk yang tahan lama lebih banyak dipilih wanita berusia dewasa dan matang. Untuk perempuan usia muda pemilihan warna juga menjadi salah satu faktor dengan presentasi cukup tinggi untuk menentukan produk yang ingin dibeli.

Dari data diatas dapat dilihat bahwa pertumbuhan bisnis pada klinik kecantikan yang sangat menjanjikan, sehingga banyak produkproduk dan produsen terus bersaing membuat produk yang unggul di bandingkan yang lain. Kepuasan konsumen menjadi salah satu kunci dalam memasarkan produk apapun, karena citra perusahaan akan sangat bergantung pada kepuasan dan loyalitas konsumennya.

Dalam mendapatkan loyalitas konsumen, banyak yang dapat dilakukan oleh produsen dalam strateginya. Memberikan pelayanan terbaik merupakan salah satu cara dalam mempertahankan loyalitas konsumen. Salah satu klinik kecantikan yang menjadi pilihan utama masyarakat Indonesia adalah klinik kecantikan Erha Skin Care.

Saat tingginya persaingan di Industri Klinik Kecantikan, Erha Skin Care dapat menunjukan kualitas tak hanya produk, namun juga pelayanannya, Klinik kecantikan Erha Skin Care adalah salah satu klinik kecantikan yang berada di Jakarta, yang berdiri sejak 28 September 1999, Erha hadir membawa warna baru dalam dunia kesehatan kulit di Indonesia. Didukung oleh dermatologist terbaik, produkproduk yang inovatif, teknologi terkini, dan pelayanan terbaik. Tim dermatologist senantiasa dikembangkan dalam programprogram terkini di bidang ilmu pengetahuan spesialis kulit dalam Erha Institute. Produkproduk dari erha merupakan formula terbaik yang telah melewati uji klinis Research \& Innovation, dan terbukti efektif serta aman dikonsumsi. Terapi-terapi di Erha terdiri dari Personal Rejuvenation Program, Personal Acne Cure Program, Personal Hair Growth \& Scalp Program, Personal Body Program, Children Dermatology, Senior Dermatology, General Dermatology.

Klinik Kecantikan Erha Skin Care dalam pelayanannya memberikan jasa tindakan dan penjualan krim kecantikan kulit wajah dan tubuh baik secara medik atau non medik dengan tujuan meningkatkan derajat kesehatan kecantikan kulit wajah dan tubuh yang optimal. Efek yang ditimbulkan dari klinik kecantikan adalah apa yang diinginkan setiap wanita pada umumnya, yaitu memiliki kulit yang cantik dan sehat. Dari adanya persaingan klinik kecantikan maka terdapat banyak pesaing dalam bidang yang sama yaitu perawatan kulit dan kecantikan. 
Peneliti memilih klinik kecantikan Erha Skin Care sebagai objek peneletian dikarenakan klinik kecantikan Erha Skin Care masuk kedalam jajaran Top Brand dalam penghargaan Top Brand Award.

Corporate Image Award 2017 merupakan penghargaan yang diberikan kepada perusahaan yang mempunyai corporate image terbaik di kategori industrinya berdasarkan survei Frontier Consulting Group. Survei ini dilakukan terhadap empat kelompok responden, yaitu manajemen/pelaku bisnis, stock holder/investor jurnalis dan masyarakat publik. Jumlah responden yang dilibatkan sebanyak 3000 responden terdiri dari 660 untuk panel publik, 1140 panel manajemen, 1020 panel investor, dan 180 panel jurnalis. Pengukuran corporate image 2017 menggunakan 4 dimensi yaitu quality, performance, responsibility, dan attractiveness.

Oleh karena alasan diatas, peneliti menentukan Klinik Kecantikan Erha Skin Care sebagai objek penelitian ini dikarenakan di Top Brand Award Klinik Kecantikan Erha Skin Care berada di peringkat ke dua sedangkan Corporate Image Award Klinik Kecantikan Erha Skin Care lebih unggul. Pada penelitian ini, peneliti ingin meneliti pengaruh service quality, customer satisfaction, dan corporate image terhadap customer loyalty. Service Quality adalah segala bentuk aktivitas yang dilakukan oleh perusahaan untuk memenuhi harapan konsumen. Menurut Hussain et al., 2015 dalam jurnal Service quality is closely related to and is often confused with customer satisfaction sehingga semakin baik pelayanan yang di berikan oleh Klinik Kecantikan Erha Skin Care maka pelanggan akan terus memilih Klinik Kecantikan Erha Skin Care sebagai pilihan terbaik dalam perawatan kecantikan.

Setelah Service Quality salah satu factor yang mempengaruhi adalah Customer Satisfaction. Customer Satisfaction merupakan perasaan senang yang dirasakan oleh pelanggan dalam menerima suatu kinerja. Customer Satisfaction mempunyai hubungan terhadap kesetiaan pelanggan. Menurut $\mathrm{Hu}$ et al., 2009; Kotler and Keller, 2009; When performance is greater than expectation, the customer is delighted. Ketika pelanggan merasa puas atas kinerja yang di berikan Klinik Kecantikan Erha Skin Care maka pelanggan tersebut akan tetap setia dengan Klinik Kecantikan Erha Skin Care.

Terakhir yaitu Corporate Image yaitu suatu pandangan baik atau buruknya suatu perusahaan tersebut. Ketika Klinik Kecantikan Erha Skin Care memiliki pandangan yang baik maka konsumen akan lebih menyukai untuk tetap berlangganan di Klinik Kecantikan Erha Skiin Care ketika Klinik Kecantikan Erha Skin Care memiliki pandangan yang buruk maka konsumen akan sulit berlangganan bahkan setia sengan Klinik Kecantikan Erha Skin Care.

\section{Service Quality}

Menurut Santoso Jessica (2003) Service Quality as being "the overall evaluation of a specific service firm that results from comparing that firm's performance with the customer's general expectations of how firms in that industry should perform." Prentice (2013), "service quality has been referred to as an abstract and elusive construct because of the unique characteristics of services, namely, intangibility, heterogeneity, inseparability and perishability."

Berdasarkan beberapa definisi di atas, maka Service Quality dapat disimpulkan sebagai kualitas kinerja yang diberikan perusahaan kepada pelanggan guna untuk memenuhi dan memuaskan harapan pelanggan, sehingg aapa yang diberikan dan didapatkan pelanggan sesuai dengan harapan pelanggan itu sendiri.

\section{Customer Satisfaction}

Menurut Kotler dan Keller $(2016,153)$ "Satisfaction is a person's feelings of pleasure or dispoinment that result from compairing a product or service's perceived performance (or outcome) to expectations." 
Menurut Pine dan Gilmore (1998) dalam Bridson and Mavondo (2011) "customer satisfaction is the extent of the customer's connection with the experience, with absorption on one end of the continuum, suggesting observation and standing back from the experience."

Berdasarkan definisi-definisi diatas dapat disimpulkan Customer Satisfaction adalah persepsi pelanggan ketika menggunakan suatu produk atau jasa sehingga menimbulkan perasaan senang atau puas yang diterima oleh pelanggan setelah merasakan produk atau jasa yang sudah digunakan (Briliana 2013).

\section{Corporate Image}

Menurut Clow dan Baack $(2014,40)$ corporate image adalah "A corporate image summarizes what the company stands for as well as how it is known in the marketplace." Menurut Keller (2013:399) "Corporate Image is consumer associations to the company or corporation making the product or providing the service." Sesuai dengan berbagai penjelasan diatas dapat ditarik kesimpulan bahwa Corporate Image adalah segala pandangan konsumen terhadap suatu perusahaan melalui produk atau jasa yang ditawarkannya.

\section{Customer Loyalty}

Menurut Kotler dan Keller $(2016,153)$, Customer Loyalty adalah "A deeply held commitment to rebuy or repatronize a preferred product or service in the future despite situational influences and marketing efforts having the potential to cause switching behavior." "As customer loyalty is considered a vital objective for a firm's survival and growth, building a loyal customer base has not only become a major marketing goal."

Berdasarkan definisi di atas dapat disimpulkan bahwa customer loyalty merupakan kesetiaan konsumen terhadap suatu produk barang atau jasa yang ditawarkan.

\section{METODE PENELITIAN}

Penelitian ini dirancang dengan menggunakan metode deskriptif dan metode kausalitas. Penelitian ini menggambarkan setiap variabel sesuai dengn karakteristiknya. Menurut Metode deskriptif menurut Sekaran dan Bougie (2016:43) adalah "to design collect data that describe characteristics of object, events, or situation". Tujuan dari penelitian deskriptif secara lebih tepat adalah untuk menyajikan kepada peneliti sebuah profil atau beberapa faktor fenomena yang menarik dari individu, organisasi, dan orientasi industri, dan berbagai perspektif lain.

Obyek dalam penelitian ini adalah klinik kecantikan Erha skin care. Pengumpulan data dalam penelitian ini menggunakan kuesioner yang disebarkan di Jakarta pada bulan April 2018. Responden dalam penelitian ini adalah orang yang menggunakan produk/jasa klinik kecantikan Erha skin care dengan kriteria sebagai berikut: responden minimal berumur 20 tahun, responden pernah menggunakan produk/jasa klinik kecantikan Erha skin care, responden yang berada di Jakarta,.

Menurut Hair et al., (2014:122) menjelaskan "The researcher generally would not factor analyze a sample of fewer than 50 observation and preferably the sample size should be 100 or large". Jumlah kuisioner yang disebarkan sebanyak 130 dan jumlah sampel yang di ambil oleh peneliti sebanyak 100 responden. Variabel yang digunakan terdiri dari Service Quality, Customer Satisfaction, Corporate Image, Customer Loyalty.

Penelitian ini menggunakan skala likert. Menurut Sekaran dan Bougie (2016:215), skala likert adalah "likert scale is designed to examine how strongly subjects agree or disagree with statements on a five point with following anchors: strongly disagree, disagree, neither agree nor disagree, agree, strongly agree". Responden diberikan pertanyaan dengan 
pilihan jawaban 1 = sangat tidak setuju sampai $5=$ sangat setuju.
Berdasarkan hasil pengolahan kuisioner, maka karakteristik responden sebagai berikut:

\section{HASIL}

Tabel 1 Karakteristik Responden

\begin{tabular}{lll}
\hline Keterangan & & Jumlah \\
\hline Jenis Kelamin & Pria & 9 \\
& Wanita & 91 \\
\hline Umur & $20-25$ tahun & 90 \\
& $26-30$ tahun & 8 \\
Pendidikan Terakhir & $31-35$ tahun & 2 \\
& Diploma & 5 \\
Pekerjaan & S1 & 92 \\
& S2 & 3 \\
& Ibu rumah tangga & 3 \\
Menggunakan jasa Erha skin care & Karyawan swasta/negri & 92 \\
Berapa kali menggunakan jasa erha & Yiraswasta & 1 \\
skin care & Belum kerja & 4 \\
\hline
\end{tabular}

Sumber: Data kuesioner diolah menggunakan SPSS

Penelitian ini menggunakan model analisis regresi linier untuk pembuktian hipotesis penelitian.

Tabel 2 Hasil Analisis Regresi Berganda

\begin{tabular}{lllll}
\hline Model & $\begin{array}{l}\text { Unstandardized } \\
\text { Coefficients }\end{array}$ & $\begin{array}{l}\text { Standardized } \\
\text { Coefficients }\end{array}$ & $t$ & Sig. \\
\hline
\end{tabular}

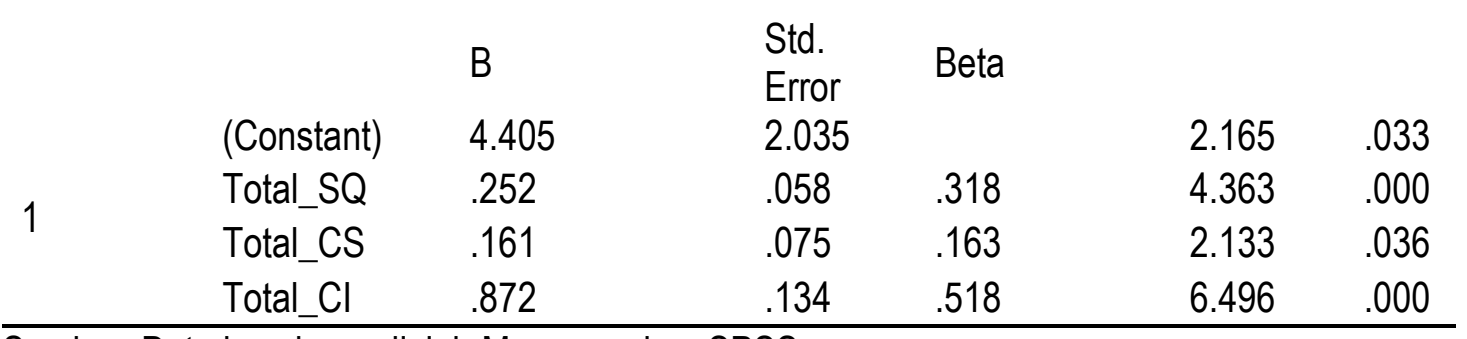

Sumber: Data kuesioner diolah Menggunakan SPSS

Berdasarkan hasil diatas hubungan service quality $\left(X_{1}\right)$, customer satisfaction $\left(X_{2}\right)$, corporate image $\left(X_{3}\right)$, dan customer loyalty $(Y)$ dapat ditulis dalam persamaan berikut

$$
\begin{aligned}
& Y=4,405+0,252 \times 1+0,161 \times 2+0,872 \times 3+e \\
& \text { Keterangan: } \\
& Y \quad=\text { Customer Loyalty }
\end{aligned}
$$


$\mathrm{X} 1=$ Service Quality

$\mathrm{X} 2=$ Customer Satisfaction

X3 = Corporate Image

Dari persamaan tersebut menyatakan bahwa variable Service Quality $\left(X_{1}\right)$, Customer satisfaction $\left(X_{2}\right)$ dan Corporate Image $\left(X_{3}\right)$ berpengaruh positif terhadap Customer Loyalty $(Y)$.

Ketetapan fungsi regresi dalam menaksir nilai actual dapat diukur dari Goodness of Fitnya, diukur dengan nilai $F$, uji $t$, dan nilai koefisien determinasi. Uji $\mathbf{F}$ digunakan untuk menguji ada tidaknya pengaruh variable bebas (independen) terhadap variable terikatnya (dependen). Berdasarkan hasil uji $F$ hitung sebesar 40,365 dengan tingkat signifikasi 0,000 . Karena $F$ hitung $(40,365)>F$ tabel $(2,70)$ dan tingkat sig $0,000<0,05$ maka model regresi dapat digunakan untuk memprediksi customer loyalty $(\mathrm{Y})$ atau dikatakan bahwa variable service quality $\left(X_{1}\right)$, customer satisfaction $\left(X_{2}\right)$, dan corporate image $\left(X_{3}\right)$ mempunyai pengaruh secara bersama - sama terhadap variable customer loyalty (Y).

Tabel 3 Hasil Uji $\mathbf{F}$

\begin{tabular}{|c|c|c|c|c|c|}
\hline Model & \multicolumn{2}{|c|}{ Sum of Squares Df } & Mean Square & $\mathrm{F}$ & Sig \\
\hline 1 Regression & 337.418 & 3 & 112.473 & 40.365 & $.000^{b}$ \\
\hline Residual & 267.492 & 96 & 2.786 & & \\
\hline Total & 604.910 & 99 & & & \\
\hline
\end{tabular}

Sumber: Data kuesioner diolah menggunakan SPSS

Uji t yaitu menguji signifikasi pengaruh variable independen terhadap dependen secara individual

Tabel 4 Hasil Uji t

\begin{tabular}{lll}
\hline Variabel Bebas & t hitung & Signifikansi \\
\hline Service Quality & 4,363 & 0,000 \\
Customer Satisfaction & 2,133 & 0,036 \\
Corporate Image & 6,496 & 0,000 \\
\hline
\end{tabular}

Sumber: Data kuesioner diolah menggunakan SPSS

Hasil uji t adalah sebagai berikut:

Pengujian hipotesis pertama diperoleh nilai $t$ hitung sebesar 4,363 dengan nilai sig. sebesar $0,000<0,05$. Artinya, service quality $\left(X_{1}\right)$ memiliki pengaruh terhadap customer loyalty $(Y)$.

Hasil uji hipotesis kedua diperoleh nilai t sebesar 2,133 dengan nilai sig. sebesar 0,036 > 0,05 . Artinya, customer satisfaction $\left(X_{2}\right)$ memiliki pengaruh terhadap customer loyalty $(\mathrm{Y})$.

Hasil uji hipotesis ketiga diperoleh nilai t sebesar 6,496 dengan nilai sig. 0,000 $<0,05$.
Artinya corporate image $\left(X_{3}\right)$ memiliki pengaruh terhadap customer loyalty $(Y)$.

Berdasarkan tabel 5 angkar $\mathrm{R}$ adalah sebesar 0,747 yang berarti korelasi berganda antara service quality, customer satisfaction, dan corporate image memiliki hubungan yang kuat terhadap customer loyalty karena terletak di antara 0,60-0,799 ( Neolaka 2014, 129). 


\section{PENUTUP}

Hasil penelitian ini menunjukan bahwa terdapat pengaruh service quality, customer satisfaction dan corporate image terhadap customer loyalty pada klinik kecantikan Erha skin care di Jakarta.

Hasil penelitian ini berguna bagi perusahaan untuk memberikan edukasi tentang produk/jasa yang mereka jual dan meningkatkan kesetiaan konsumen, serta bagi pihak lain sebagai sumber referensi dan informasi tambahan dan bahan pertimbangan bagi para pihak yang ingin melakukan penelitian lebih lanjut.

\begin{abstract}
Adapun keterbatasan yang terdapat dalam penelitian ini antara lain (1) Keterbatasan waktu, materi, wilayah, dan tenaga yang di perlukan dalam menyelesaikan penelitian ini; (2) keterbatasan responden dalam pengertian kuisioner sehingga membuat responden tidak berani mengisi kuisioner. Untuk penelitian selanjutnya direkomendasikan untuk meneliti hubungan pengujian statistik menggunakan aplikasi SPSS dengan judul penelitian pengaruh Service Quality, Customer Satisfaction, dan Corporate Image terhadap Customer loyalty klinik kecantikan Erha skin care di tempat yang berbeda.
\end{abstract}

\section{REFERENCES:}

Bridson, Kerrie.2011. "Corporate Image in the leisure service sector." Journal of Services Marketing, 25(3), 190201, https://doi.org/10.1108/08876041111129173.

Briliana, Vita. 2013. Pengaruh Kepuasan , Komitmen, Manfaat Sosial dan Special Treatment Benefits Terhadap Loyalitas Pelanggan. Jurnal Bisnis dan Akuntansi. 15(1).

Clow, Kennethe, dan Back Donald. 2014. Integrated advertising, promotion and marketing. $6^{\text {th }}$ Edition. US of America: Pearson.

Hair, Joseph. F., Wiliam C Black, , Barry J Babin, and Rolph E Anderson 2014. Multivariate Data Analysis. United Kingdom: Pearson Education Limited.

Kartini. 2017. "Industri Kecantikan di Indonesia Alami Pertumbuhan Pesat." Dalamhttp://majalahkartini.co.id/modekecantikan/kecantikan/industri-kecantikan-di-indonesia-alamipertumbuhan-pesat/ (di akses pada 23 Febuari 2018).

Keller, Kevin Lane. 2013. Strategic Brand Management Building, Measuring, and Brand Equity. $4^{\text {th }}$ Edition. Pearson Prentice Hall.

Kotler. Philip, dan Kevin Lane Keller. 2016. Marketing Management $15^{\text {th }}$ Edition. England: Pearson Education Limited.

Mandhachitara, Rujirutana. 2011. "A model of customer loyalty and corporate social responsibility." Journal of Services Marketing, 25(2), 122-133, https://doi.org/10.1108/088760411111119840.

Prentice, Catherine. 2013. "Service quality perceptions and customer loyalty in casinos." International Journal of Contemporary Hospitality Management, 25(1), 49-64, https:// doi.org/10.1108/09596111311290219.

Santoso, Jessica. 2003. "E-Service Quality: A Modal of Virtual Service Quality Dimensions." Managing Service Quality: An International Journal, 13(3), 233-246, https://doi.org/10.1108/09604520310476490.

Sekaran, Uma. and Roger Bougie. 2016. Research Methods for Business. United Kingdom: John Wiley; Sons LTD.

Sigma Research. "Tren dan Prilaku Pasar Kosmetik Indonesia Tahun 2017" Dalam http://sigmaresearch.co.id/trendan-perilaku-pasar-kosmetik-indonesia-tahun-2017/ (di akses pada 3 Maret 2018).

Top Brand. 2017. "Top Brand" dalam http://www.topbrand-award.com/top-brand-survey/surveyresult/top_brand_index_2016_fase_2 (di akses pada 3 Maret 2018). 
